\title{
CARACTERÍSTICAS DE TIPO E CONDIÇÃO CORPORAL EM VACAS HOLANDÊS E MESTIÇAS HOLANDÊS X JERSEY
}

(Evaluation of body traits and condition score in Holstein and crossbred Holstein X Jersey cattle)

Roberto Parizotto Filho ${ }^{1}$, André Thaler Neto, Marciel França, Mauricio Camera

${ }^{1}$ Correspondência: b_parizotto@hotmail.com

RESUMO: $O$ trabalho objetivou comparar vacas mestiças Holandês $X$ Jersey com vacas da raça Holandês quanto à conformação e condição corporal. Foi realizado em quatro rebanhos leiteiros que possuem animais Holandês e cruzadas Holandês $X$ Jersey, as quais foram avaliadas para 22 características lineares de tipo e condição corporal. Foram avaliadas somente vacas lactantes, com medidas métricas para as características mensuráveis. Para as medidas subjetivas de conformação, utilizou-se escala de 1 a 9 , com base na metodologia canadense de classificação linear. Para escore de condição corporal, a escala utilizada foi de 1 a 5 . Foram coletadas informações de produção de leite, idade e estágio de lactação das vacas. Os dados foram submetidos à análise de variância, sendo o modelo estatístico composto pelo grupamento genético, paridade, estágio de lactação, rebanho e interações entre estas variáveis. A relação entre as medidas de classificação linear e escore de condição corporal foi analisada por análise multivariada (análise fatorial). Vacas mestiças apresentaram produção de leite inferior às Holandês (23,6 X 26,5 kg; $P<0,0001)$. Nas características de sistema mamário, observou-se melhor pontuação para clivagem de úbere $(\mathrm{P}<0,01)$ e colocação de tetos posteriores em mestiças $(P<0,01)$, com piores resultados para profundidade de úbere e udder clearance $(P<0,0001)$. Vacas Holandês apresentaram melhor conformação de ângulo de casco $(P<0,001)$, com pior qualidade óssea $(P<0,01)$, bem como maior estatura $(P<0,0001)$ e menor profundidade corporal e escore de condição corporal frente às cruzadas $(P<0,01)$. Observou-se garupas mais largas $(P<0,0001)$, menos inclinadas $(P<0,0001)$ e com força de lombo inferior $(P<0,05)$ em vacas Holandês. A análise fatorial demonstrou relação negativa da produção de leite com queda de úbere e positiva com: profundidade corporal, angulosidade, qualidade óssea, largura e textura de úbere. Demonstrou ainda associação positiva entre menor ordem de parto com altura, profundidade, clivagem e textura de úbere.

Palavras-chave: cruzamento; garupa; sistema mamário; força leiteira; pernas e pés

\begin{abstract}
This work compared body measurements and body condition between Holstein $X$ Jersey crossbred and Holstein cows. It was performed in four dairy herds with both Holstein and Holstein X Jersey cows, which was measured for 22 type traits and body condition score. There was measured lactating cows, with metric measurements for the measurable traits, a 1-5 scale for body condition score and a subjective score of 1-9, based on Canadian evaluation method to the notmeasurable traits. Milk yield, age and days in milk (DIM) data was collected. The data were submitted to ANOVA with repeated measures, being the statistic model compound by genetic grouping, parity, DIM, herd and the interaction of genetic grouping with parity and DIM. Factorial analysis was done to analyze the relationship between the body measurements and body condition score data in each genetic grouping. Difference was detected $(P<0,0001)$ between genetic grouping for milk yield, with advantage to Holstein cows $(23,6 \times 26,5 \mathrm{~kg})$. In the udder traits, crossbred cows showed better scores for udder cleavage $(P<0,01)$ and rear teat placement $(P<0,01)$, but with worse results for udder depth and udder clearance $(P<0,0001)$. Holstein cattle had better score for foot angle $(P<0,001)$, but with worse bone quality $(P<0,01)$. Holstein cows was taller $(P<0,0001)$, had shallower body depth and worse body condition score $(P<0,01)$ in comparison to crossbred cows. The Holstein cows showed wider $(P<0,0001)$ and less sloped rumps $(P<0,0001)$, but worse loin strength $(p<0,05)$ than crossbred cows. Factorial analysis showed negative relationship of milk yield with udder depth and clearance and positive with: body depth, angulosity, bone quality and udder width and texture. Also, there was a relationship between younger cows with taller and shallower udders, better udder clivage and texture.
\end{abstract}

Key Words: analysis of variance; mammary system; milk yield; rump; udderclearance 


\section{INTRODUÇÃo}

Com seu clima subtropical e temperaturas amenas, a região Sul do Brasil tem sua produção de leite baseada especialmente na raça leiteira especializada Holandês e, em segundo plano, Jersey (THALER NETO et al., 2013). Após décadas de seleção para aumento de produção, principalmente em rebanhos da raça Holandesa, conseguiu-se um aumento significativo na quantidade de leite produzido por animal. Em contrapartida, fatores relacionados à saúde, longevidade e fertilidade tiveram um declínio acentuado ((BJELLAND et al., 2011). Uma alternativa para amenizar este declínio funcional é a seleção para conformação dos animais. Esta avaliação, denominada classificação linear para tipo, auxilia na seleção de indivíduos mais produtivos e longevos dentro dos rebanhos (HOLSTEIN CANADA, 2014; CARAVIELLO et al., 2003, 2004), com destaque para a importância de uma boa conformação de aprumos e sistema mamário para obterse animais mais funcionais.

Outra estratégia para melhorar o desempenho dos rebanhos é o cruzamento entre raças especializadas, principalmente entre as raças Holandês e Jersey, o qual têm se mostrado promissor em melhorar a rentabilidade dos rebanhos, através de heterose e complementaridade entre raças. Apesar de haver considerável quantidade de dados gerados sobre aspectos produtivos do cruzamento, há poucos trabalhos que abordam a conformação de vacas mestiças, como os de Heins et al. (2008, 2011), Schaeffer et al. (2011) e Bjelland et al. (2011), sendo todos da América do Norte. Estes trabalhos abordam um número restrito de características de tipo e diferem entre si quanto à forma de avaliação das mesmas, dificultando a comparação entre os resultados. Isto ocorre, por exemplo, para a profundidade do úbere, avaliada como distância do úbere em relação ao jarrete, como avaliado por Schaeffer et al. (2011) ou ao solo, como avaliado por Heins et al. $(2008 ; 2011)$ e Bjelland et al. (2011). Esta diferença nas metodologias não permite saber se a diferença nos resultados para profundidade da glândula mamária são devidas à diferença de altura entre vacas puras e mestiças ou se realmente há diferença na queda da glândula mamária.

Considerando a escassez de informações sobre o tema, realizou-se este trabalho, visando comparar vacas Holandês e mestiças Holandês $X$ Jersey quanto às características lineares para tipo e condição corporal em condições de produção em clima subtropical do sul do Brasil.

\section{MATERIAL E MÉTODOS}

O trabalho foi realizado em quatro propriedades leiteiras localizadas em Carambeí - PR (Propriedade 1), Lages SC (Propriedade 2), Curitibanos - SC (Propriedade 3) e Herval D'Oeste - SC (Propriedade 4), variando de 25 a 150 vacas em lactação. Todas realizavam duas ordenhas diárias em salas tipo espinha de peixe. O sistema alimentar nas quatro propriedades consistia no uso de pastagem com suplementação concentrada e volumosa. A base forrageira era similar. Na propriedade 1 consistia das cultivares perenes de verão quicuio (Penissetum clandestinum) e tifton 85 (Cynodon spp.), intercalados com aveia (Avena sp.) e azevém (Lolium sp.) no outono / inverno. Na propriedade 2 consistia em capim quicuio (Penissetum clandestinum) e capim sudão (Sorghum sudanense L) no verão, festuca (Festuca arundinacea Schreb), trevos vermelho (Trifolium pratense L.) e branco (Trifolium repems L.), aveia (Avena sp.) e azevém (Lolium sp.) no inverno/primavera, enquanto nas propriedades 3 e 4 a base forrageira 
consistia em tifton 85 e jiggs (Cynodon spp. e Cynodon dactylon) no verão e aveia (Avena sp.) e azevém (Lolium sp.) no inverno/primavera. Em todas as propriedades as vacas eram suplementadas com concentrado e silagem de milho, porém esta suplementação era maior na propriedade 1 em relação às demais.

Os rebanhos eram formados por vacas mestiças Holandês $X$ Jersey $e$ puras Holandês, sendo incluídas no estudo as gerações $\mathrm{F} 1$ e F2 do sistema de cruzamento rotacionado, sendo as F2 filhas de touro Holandês, apresentando, respectivamente, $50 \%$ Holandês X $50 \%$ sangue Jersey ou $75 \%$ Holandês $X 25 \%$ sangue Jersey. Todas as propriedades utilizavam inseminação artificial, sendo que para a formação das vacas mestiças as propriedades 1 , 2 e 4 utilizaram programas de cruzamento iniciado a partir da utilização de sêmen importado de touros Jersey provados em vacas Holandês e na propriedade 3 a partir da utilização de sêmen importado de touros Holandês provados em vacas Jersey.

Foram realizadas três avaliações em cada propriedade, com intervalo de 6 a 12 semanas. Foram obtidos dados das vacas em lactação através da mensuração direta das características morfológicas dos animais e da coleta de informações do banco de dados das propriedades. Coletou-se dados de datas de nascimento e parto, produção leiteira, utilizando o controle mais próximo à data da visita. As características de tipo foram avaliadas durante o manejo de ordenha, sendo a avaliação da conformação de úbere realizada antes da ordenha e as demais características após a ordenha, durante a suplementação.

\section{AVALIAÇÃO DA CONFORMAÇÃO}

Avaliou-se 22 características de conformação em as vacas em lactação sendo 21 características lineares para tipo oficiais e a característica não-oficial medida denominada udder clearance, descrita por Heins et al. $(2008,2011)$ e Bjelland et al. (2011), representando a distância do piso do úbere em relação ao solo. As características lineares de tipo foram avaliadas com critérios baseados na metodologia canadense de avaliação, utilizando escala de 1 a 9 , sendo a metodologia de avaliação descrita no quadro 1.

\begin{tabular}{|c|c|}
\hline Atributo & Descriçăo \\
\hline \multicolumn{2}{|r|}{ SISTEMA MAMARIO } \\
\hline Udder Clearance & $\begin{array}{l}\text { Avaliaḉ̧o da distáncia do piso do úbere em relaçáo ao solo, medida em } \\
\text { centimetros. }\end{array}$ \\
\hline $\begin{array}{l}\text { Inserção de úbere } \\
\text { anterior }\end{array}$ & $\begin{array}{l}\text { Avaliaçăo da inserçâa de úbere ao abdómen, com pontuaçăo proporciona } \\
\text { á área de contato com a parede abdominal. Escala subjetiva de } 1 \text { a } 9 \text {. }\end{array}$ \\
\hline $\begin{array}{l}\text { Comprimento de tetos } \\
\text { anteriores }\end{array}$ & Comprimento do teto, avaliado da base à sua extremidade. \\
\hline $\begin{array}{l}\text { Colocaçâo de tetos } \\
\text { anteriores e } \\
\text { posteriores }\end{array}$ & $\begin{array}{l}\text { Visualização dos tetos pela vista posterior. Atribui-se escore subjetivo } \\
\text { variando de } 1 \text { (tetos com origem lateral ao centro do úbere) a } 9 \text { (tetos } \\
\text { com origem medial ao mesmo). }\end{array}$ \\
\hline Textura de úbere & $\begin{array}{l}\text { Analisa-se o quanto a pele do ubere é fina, pregueada, movele ausente } \\
\text { de pêlos. Escala de } 1 \mathrm{a} \theta \text {. }\end{array}$ \\
\hline Profundidade çúbere & Distância do piso do úbere à articulação tibio-társica (jarrete). \\
\hline Udder Clearance & Distância do piso do úbere ao solo. \\
\hline Altura de úbere posterior & r Distáncia entre a porçăo inferior da vulva e superior da glândula mamária. \\
\hline Largura de ubere & Mensuraçáo da largura do ubere pela via posterior. \\
\hline $\begin{array}{l}\text { Ligamento médio de } \\
\text { úbere }\end{array}$ & $\begin{array}{l}\text { Avalia de forma subjetiva a intensidade com a qual o ligamento médo de úbere } \\
\text { cóva os hemisférios da glândula mamária. Escala de } 1 \text { a } 8 \text {. }\end{array}$ \\
\hline \multicolumn{2}{|r|}{ PERNASEPES } \\
\hline Angulo de Casco & $\begin{array}{l}\text { Observa-se o ángulo que a banda coronária do casco forma com o solo, } \\
\text { aumentando a pontuaçăo à medida que o ồngulo aumenta. }\end{array}$ \\
\hline Profundidadede taläo & Tamanho do taläo do casco. Medido em cm. \\
\hline Qualidade óssea & $\begin{array}{l}\text { Avalia subjetivamente o refinamento das estruturas ósteo-articulares da } \\
\text { regiäo proxima ao jarrete. Escala de } 1 \text { a } 9 \text {. }\end{array}$ \\
\hline Pernas vista posterior & $\begin{array}{l}\text { Traça-se um prumo imaginário da ponta do isquiol perpendicular ao solo e } \\
\text { avalia-se a posicăo do jarrete em relacãáo ao prumo. A medida que o } \\
\text { jarrete posiciona-se medialmente ao prumo, a pontuaçáo aproxima-se de } \\
\text { g. }\end{array}$ \\
\hline \multicolumn{2}{|r|}{$\begin{array}{l}\text { FORÇA LEITEIRA } \\
\text { Descriçäo }\end{array}$} \\
\hline Estatura & Distância do solo à união lombo-sacra da coluna vertebral. \\
\hline Nivelamento de dorso & Diferença entre a estatura do animal na garupa e na ponta das escápulas. \\
\hline Profundidadecorporal & $\begin{array}{l}\text { Avalia subjetivamente o quanto a cavidade abdominal projeta-se abaixo do } \\
\text { olecrano da ulna e aproxima-se do solo. Quanto mais profunda, maior a } \\
\text { pontuaçäo. }\end{array}$ \\
\hline Angulosidade & $\begin{array}{l}\text { Atributo subjetivo referente ao espaçamento e direçăo das costelas, grau } \\
\text { de descarnamento e refinamento da estrutura corporal. }\end{array}$ \\
\hline \multicolumn{2}{|r|}{$\begin{array}{l}\text { GARUPA } \\
\text { Descriçäo }\end{array}$} \\
\hline Angulo de garupa & Diferença da estatura da ponta do isquio com a extremidade do ileo. \\
\hline Largura de garupa & Distäncia entre os dois ísquios, medida pela vista posterior. \\
\hline Força de lombo & $\begin{array}{l}\text { Característica subjetiva, que considera a largura do lombo, definiçâo das } \\
\text { vértebras e uniäo à garupa. }\end{array}$ \\
\hline
\end{tabular}

\section{ESCORE DE CONDIÇÃO CORPORAL}

Utilizou-se a metodologia de Ferguson et al. (1994), baseando a avaliação na visualização das tuberosidades isquiáticas, ilíacas, ligamentos íleo-sacral e ísquiococcígeo, e dos processos transversos e espinhais da coluna vertebral, atribuindo pontuações de 1 a 5 , com intervalos de 0,25 , sendo 1 para animais emaciados e 5 para $s$ obesos. A avaliação foi realizada juntamente com a avaliação para tipo. 


\section{ANÁLISE ESTATÍSTICA}

Os dados foram analisados através de técnicas univariadas e multivariadas, utilizando-se 0 pacote estatístico SAS.

Os dados foram submetidos à análise de variância como medidas repetidas no tempo para cada vaca, utilizando-se o procedimento MIXED, com estrutura de covariância auto regressiva. Os dados foram previamente testados para normalidade dos resíduos pelo teste de Shapiro Wilks. As variáveis independentes ordem de parto e estágio de lactação foram agrupadas em classes, sendo a paridade agrupada como primeiro, segundo e três ou mais partos e o estágio de lactação em até 100 dias, 100 a 200 e mais de 200 dias de lactação. Para as características de tipo dos grupamentos sistema mamário e força leiteira e, para escore de condição corporal foi utilizado o seguinte modelo estatístico:

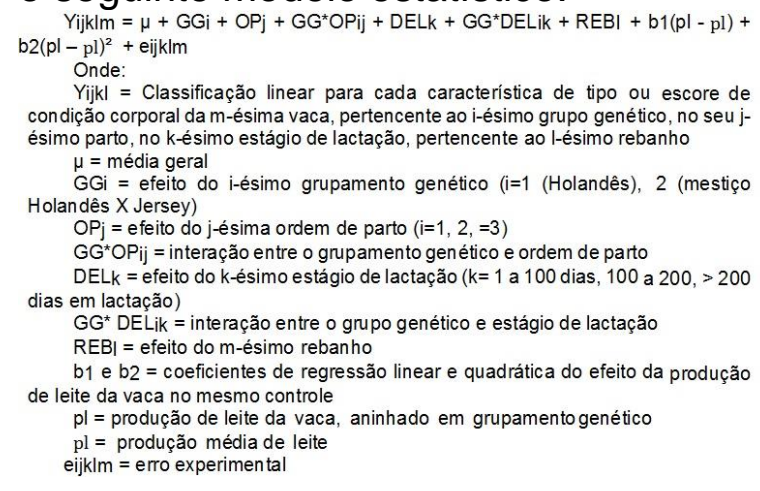

Para as categorias pernas e pés e garupa foi empregado modelo estatístico similar ao acima descrito, sem a covariável produção de leite. Visando caracterizar a população em estudo a produção de leite também foi avaliada como variável dependente.

A relação conjunta entre as medidas de classificação linear, ECC, grupamento genético, produção de leite, paridade e estágio de lactação foi avaliada pela técnica de análise multivariada análise fatorial. Os dados foram previamente padronizados pelo procedimento STANDARD e a análise fatorial realizada utilizando 0 procedimento FACTOR, com rotação Promax.

\section{RESULTADOS}

Vacas mestiças Holandês $x$ Jersey apresentaram produção menor de leite do que as puras Holandês $(P<0,0001)$, sendo os valores médios \pm erro- padrão de 23,64 $\pm 0,606$ e $26,48 \pm 0,596$ litros de leite/dia, respectivamente), sendo também influenciada pela ordem de parto e estágio de lactação (DEL), sendo as maiores produções em vacas multíparas e no terço inicial de lactação $(P<0,0001)$. Em nenhuma característica avaliada houve interação do grupo genético com paridade e com DEL $(P>$ 0,05).

\section{SISTEMA MAMÁRIO}

Houve diferença entre grupamentos genéticos para ligamento médio de úbere, colocação de tetos posteriores, profundidade de úbere $\mathrm{e}$ udder clearance (Tabela 1).

Tabela 1. Média dos quadrados mínimos \pm erro-padrão da média de acordo com o grupamento genético para as caracteristicas de sistema mamário.

\begin{tabular}{l|l|l|l}
\hline \multirow{2}{*}{ Característica de tipo } & Grupamento Genético \\
\cline { 2 - 5 } & Holandês & Holandês X Jersey & $P$ \\
\hline Altura de úbere $(\mathrm{cm})$ & $23,78 \pm 0,46$ & $21,88 \pm 0,49$ & 0,603 \\
Largura de úbere $(\mathrm{cm})$ & $16,52 \pm 0,24$ & $16,57 \pm 0,27$ & 0,166 \\
Coloc. tetos anteriores1 & $4,42 \pm 0,11$ & $4,29 \pm 0,12$ & 0,787 \\
Coloc.tetos posteriores1 & $6,78 \pm 0,12$ & $6,18 \pm 0,13$ & 0,005 \\
Tamanho tetos $(\mathrm{cm})$ & $6,76 \pm 0,15$ & $6,37 \pm 0,16$ & 0,575 \\
Profund. de úbere $(\mathrm{cm})$ & $8,61 \pm 0,62$ & $5,46 \pm 0,64$ & $<0,001$ \\
Udder clearance $(\mathrm{cm})$ & $62,18 \pm 0,73$ & $56,53 \pm 0,75$ & $<0,001$ \\
Inserção úbere anterior1 & $5,79 \pm 0,17$ & $5,16 \pm 0,18$ & 0,573 \\
Ligamento médioTextura de úbere1 & $5,53 \pm 0,16$ & $6,06 \pm 0,18$ & 0,450 \\
\hline
\end{tabular}
1Escala de 1 a 9

Vacas mestiças Holandês $X$ Jersey apresentaram úberes $3,15 \mathrm{~cm}$ mais profundos e $5,68 \mathrm{~cm}$ mais próximo do solo (udder clearance) do que vacas puras (Tabela 1). Ambas características foram influenciadas pela ordem de parto $(P<0,0001)$ e produção leiteira $(P<0,05)$, com úberes mais caídos em vacas mais produtivas e com maior paridade.

Vacas mestiças apresentaram melhor ligamento médio (Tabela 1). Foram observadas também melhores 
pontuações para este atributo em vacas mais produtivas $(P=0,0034)$ e com menor ordem de partos $(P<0,01)$.

As características de úbere anterior e posterior não foram afetadas pelo grupamento genético (Tabela 1), porém apresentaram uma relação positiva com a produção de leite.

Dentre as características relacionadas a tetos a única diferença racial observada foi um posicionamento mais concêntrico de tetos posteriores nas vacas puras Holandês (Tabela 1 ).

\section{PERNAS E PÉS}

As variáveis ângulo de casco e qualidade óssea diferiram entre os grupamentos genéticos (Tabela 2). Vacas da raça Holandês apresentaram cascos mais íngremes (Tabela 2), assim como vacas multíparas em relação às primíparas $(P=0,01)$. Entretanto, as vacas mestiças Holandês $X$ Jersey apresentaram maior qualidade óssea (Tabela 2).

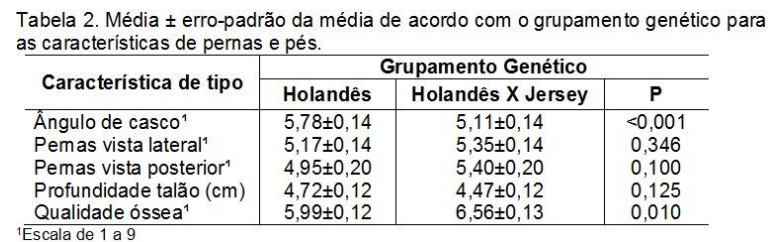

Nas características pernas vista lateral e pernas vista posterior não houve diferença entre grupamentos genéticos $(P>0,05)$, tampouco efeito de ordem de parições e estágio de lactação.

\section{FORÇA LEITEIRA}

Neste grupamento, detectou-se diferença racial em estatura, profundidade corporal e escore de condição corporal (ECC) (Tabela 3). Vacas Holandês são, em média, 7 centímetros mais altas que as mestiças, enquanto as mestiças apresentam maior profundidade corporal, sendo esta característica também influenciada positivamente pela ordem de parto $(P<0,0001)$ e produção de leite $(P=0,02)$.

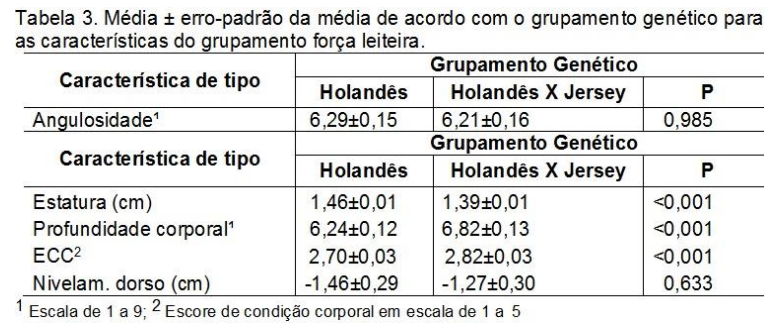

Vacas mestiças Holandês $X$ Jersey apresentaram maiores escores de condição corporal durante a lactação (Tabela 3). O ECC diminuiu à medida que aumenta o número de parições $(\mathrm{P}<$ 0,01 ) e aumentou em vacas com mais de 200 dias em lactação $(P<0,01)$. A angulosidade não foi influenciada pelo grupamento genético, sendo influenciada pela produção de leite $(P<0,05)$ e ordem de parto $(P<0,01)$, com maior angulosidade em vacas mais produtivas e com maior paridade.

\section{GARUPA}

Todas as características lineares de garupa diferiram entre grupamentos genéticos (Tabela 4). Vacas mestiças apresentaram maior inclinação de garupa, representada pela maior diferença de altura nos íleos e ísquios. Por outro lado, vacas Holandês apresentaram garupas mais largas que as vacas mestiças. Esta variável sofreu ainda efeito de ordem de parto, com garupas mais largas em animais com maior número de parições. Para a característica linear força de lombo, foi observada melhor pontuação nas vacas puras em relação às mestiças $(P=0,022)$.

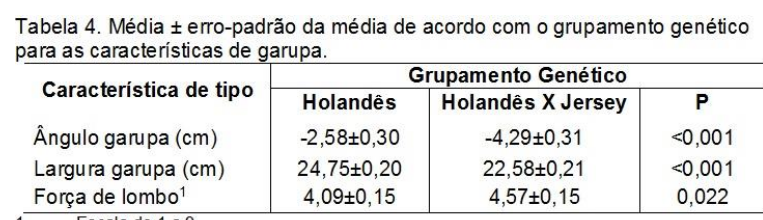

\section{ANÁLISE FATORIAL}

$\mathrm{Na}$ análise fatorial foram analisados 0 grupamento genético, codificado como 1 (mestiças Holandês $X$ Jersey) ou 2 (Holandês), ordem de 
parto, produção de leite e onze características lineares de tipo, sendo que a soma dos três primeiros fatores explicou $64,62 \%$ da variação total (Tabela 5).

No primeiro fator, as variáveis com maior fator de carga foram produção de leite e características de tipo relacionadas positivamente a esta (profundidade corporal, angulosidade, qualidade óssea, largura e textura de úbere), assim como ordem de parto e, negativamente, com indicadores de profundidade de úbere (udder clearance e profundidade de úbere), demonstrado graficamente na figura $1 \mathrm{~A}$ ).

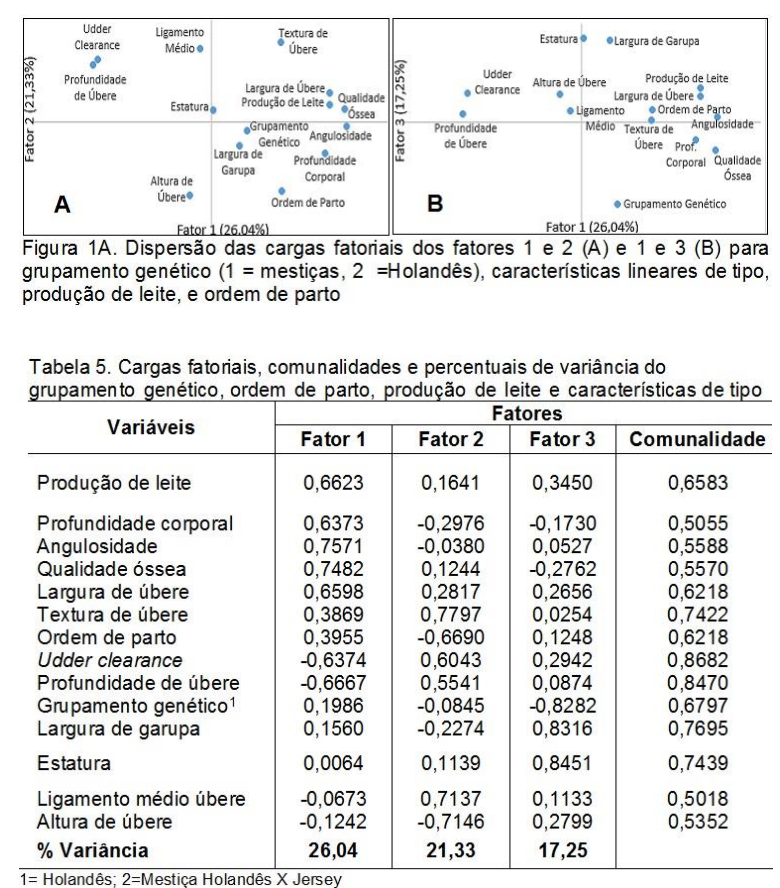

No segundo fator observa-se a relação favorável da paridade com altura de úbere posterior e contrária à profundidade, clivagem e textura de úbere (Tabela 5 e figura 1A), indicando que, com o aumento do número de partos, os úberes tendem a diminuir sua altura, aumentar a profundidade e piorar a clivagem e textura.

O terceiro fator, mostra a associação positiva entre estatura e largura de garupa e sua relação contrária a grupamento genético, indicando tamanho maior no Holandês.
No tocante às características de queda de úbere, destaca-se a maior relação de udder clearance com estatura, quando comparada com profundidade de úbere (Tabela 5 e figura $1 \mathrm{~B}$ ).

\section{DISCUSSÃO}

Vacas mestiças Holandês $x$ Jersey produziram aproximadamente $89,3 \%$ do volume diário de leite das vacas puras Holandês, percentual inferior ao relatado em outros trabalhos, como o de Lopez-Villalobos et al. (2000), que relatou uma produção de $92 \%$, Thaler Neto et al. (2013), com 94\% e Felippe (2013) com $96 \%$ do total produzido pelas puras Holandês.

Devido à importância do conjunto sistema mamário, sendo responsável por $42 \%$ da pontuação final para tipo em vacas leiteiras (VALLOTO \& NETO, 2012), maior importância é dada a estas características nos programas de melhoramento genético de bovinos de leite. Deve-se considerar que a profundidade do úbere tem sido identificada como a característica de maior impacto sobre a produção de leite, em termos de longevidade (CARAVIELLO et al., 2003), risco de novas infecções intramamárias e cronificação de infecções intramamárias subclínicas e lucratividade (PÉREZCABAL \& ALENDA, 2002). Outro motivo pelo qual existe preocupação de criadores e técnicos quanto a estas características em sistemas de cruzamento, especialmente em rebanhos originalmente da raça Holandês, é o fato de que vacas Jersey normalmente tem pior pontuação para profundidade de úbere em relação ao Holandês, como no trabalho de Theron \& Mostert (2004).

O efeito racial mais impactante foi detectado para as duas medidas que avaliam a depressão do úbere: profundidade de úbere, característica linear oficial que mede a distância do piso do úbere ao jarrete e udder 
clearance, que mede a distância do mesmo até o solo. A maior profundidade de úbere encontrada em mestiças Holandês X Jersey corrobora com Schaeffer et al. (2011), porém contrasta com Bjelland et al. (2011), que não detectaram efeito racial sobre a característica. Os resultados de udder clearance (Tabela 1) corroboram Heins et al. (2008; 2011), que também apontam úberes mais distantes do solo em vacas Holandês em relação às mestiças.

A análise fatorial (Figura 1B) mostra uma relação positiva muito intensa de estatura com udder clearence. Os resultados do fator 3 na análise fatorial (Tabela 5) mostram que a relação existente entre estatura e udder clearence não ocorre com profundidade de úbere, demonstrando que esta característica de tipo sofre menor influência de estatura do que udder clearence. Schaeffer et al. (2011) atribui a menor estatura em mestiças como um fator que colabora para esta acentuação do nível de queda de úbere.

No tocante à relação entre produção de leite e profundidade de úbere, a dispersão de cargas fatoriais do primeiro fator (Figura 1A) ilustra a correlação negativa de atributos referentes ao nível de queda de úbere com atributos relacionados positivamente à produção de leite: angulosidade, qualidade óssea, largura de úbere, profundidade corporal, ordem de parto e textura de úbere. Esta relação inversa entre nível de produção e profundidade de glândula mamária já foi descrita em diversos trabalhos, como o de Harris et al. (1992), PérezCabal \& Alenda (2002), Esteves et al. (2004), Nêmcová et al. (2007) e Campos (2012).

As relações da largura e altura de úbere posterior com produção de leite (Tabela 5 e figura 1) também foram relatadas por outros autores, dentre estes Sawa et al. (2013) e Esteves et al.
(2004), que estimaram correlações fenotípicas positivas, porém de baixa magnitude entre estas características e a produção de leite. De modo similar, a relação positiva entre textura de úbere e produção de leite (Figura 1A) condiz com os trabalhos de Esteves et al. (2004) e Campos et al. (2012), os quais descreveram correlação genética positiva de 0,35 e 0,39 , respectivamente, entre textura de úbere e produção de leite.

Embora tenha ocorrido efeito do grupamento genético em ligamento médio de úbere (Tabela 1), com superioridade para as vacas mestiças Holandês X Jersey, a diferença entre as médias dos dois grupamentos genéticos $(0,06$ pontos na escala linear) apresenta pouca relevância do ponto de vista funcional.

A ausência de efeito racial sobre inserção de úbere anterior observada concorda com os resultados de Bjelland et al. (2011). Já o efeito positivo com produção de leite diverge do observado por Němcová et al. (2007) e Harris et al. (1992), os quais observaram correlação negativa e Sawa et al. (2013), que não detectaram relação com produção. Já, a ausência de diferença entre grupamentos genéticos para tamanho de tetos corrobora com Heins et al. $(2008 ; 2011)$ e difere de Schaeffer et al. (2011), que apontaram maior tamanho de tetos em vacas mestiças Holandês $x$ Jersey.

As pontuações aferidas em colocação de tetos anteriores e posteriores (Tabela 1) são semelhantes aos dados de classificação linear para tipo relatados no Sumário Nacional de Touros da Raça Holandesa - 2013 (COSTA et al., 2013). A ausência do efeito do grupamento genético sobre a colocação de tetos anteriores observada no trabalho está de acordo com o observado por Bjelland et al. (2011), porém discorda de Heins et al. 
(2008; 2011), os quais encontraram tetos com origem mais próxima nas vacas Holandês em relação às mestiças. Uma explicação para esta incongruência de dados entre autores consiste no fato destes autores terem utilizado metodologia diferente do presente trabalho para avaliar 0 atributo, medindo a distância $(\mathrm{cm})$ entre o ponto de origem dos tetos anteriores.

Em ângulo de casco observou-se resultados semelhantes aos de Heins et al. (2008, 2011). Embora tenham utilizado metodologia diferente, com aferição direta do ângulo da ponta do casco, foi observada uma angulação de casco mais íngreme nas vacas Holandês do que nas cruzadas em ambas publicações.

A ausência de efeito racial sobre pernas vista lateral e pernas vista posterior, características de elevado impacto na classificação linear para tipo (VALLOTO \& RIBAS NETO, 2012), está de acordo com o relatado por Bjelland et al. (2011).

O resultado para ECC foi muito similar ao encontrado por Heins et al. (2008) e Vance et al. (2012). Enquanto no presente trabalho a condição corporal das vacas Holandês e mestiças foi respectivamente 2,70 e 2,82, no trabalho de Heins et al. (2008) o resultado foi semelhante, com 2,80 de ECC nas mestiças contra 2,71 das Holandês. Auldist et al. (2007) e Heins et al. (2012) avaliaram a condição corporal e o desempenho reprodutivo nos dois grupamentos genéticos, observando, além de resultados para ECC semelhantes ao presente trabalho, melhor performance reprodutiva para as vacas mestiças. A relação positiva entre ECC e indicadores reprodutivos é ilustrada por Zink et al. (2011), que observaram pior performance reprodutiva à medida que os animais são mais angulosos e possuem menos reservas corporais.
Para estatura, o efeito racial verificado (Tabela 3 ) condiz com a literatura. Heins et al. (2008, 2011), Schaeffer et al. (2011) e Bjelland et al. (2011) encontraram diferença semelhante aos do presente trabalho entre os grupamentos genéticos, sempre favorável ao Holandês. A análise fatorial (Tabela 5 e Figura 1B) mostra 0 efeito do grupamento genético sobre a característica, bem como a relação positiva de estatura sobre largura de garupa e udder clearance.

Para ângulo de garupa, a maior inclinação nas vacas mestiças Holandês $X$ Jersey encontrada (Tabela 4) é conflitante com parte da literatura. Enquanto Bjelland et al. (2011) encontrou resultados semelhantes ao presente trabalho utilizando metodologia diferente de avaliação, medindo a distância entre os íleos, Heins et al. (2011) observaram diferença no ângulo de garupa apenas em animais de segundo e terceiro partos. Para largura de garupa, os resultados da tabela 4 condizem com Heins et al. (2008,2011), com garupas mais largas em vacas Holandês. Pela análise multivariada também foi observada elevada relação desta característica com estatura (Tabela 5 e figura $1 \mathrm{~B}$ )

\section{CONCLUSÃO}

As vacas mestiças Holandês $\mathrm{x}$ Jersey apresentam menor estatura, com produção de leite menor do que vacas Holandês, porém apresentam maior escore de condição corporal e profundidade corporal.

Úberes de vacas mestiças apresentam melhores ligamentos médios, tetos posteriores mais centralizados, entretanto úberes mais profundos e próximos ao solo, destacando a importância da seleção para profundidade de úbere em programas de cruzamento entre Holandês $x$ Jersey. 
A relação das medidas de profundidade de úbere com estatura e produção de leite mostrou que, apesar de avaliarem o mesmo atributo, são influenciadas de forma diferente, sendo udder clearance mais afetada pela estatura do que profundidade de úbere.

Vacas mestiças Holandês X Jersey apresentaram menor pontuação para ângulo de casco, maior qualidade óssea, bem como garupa mais estreita, mais inclinada e com maior força de lombo

\section{AGRADECIMENTOS}

Aos produtores Ricardo Guimarães, Alexandre Gemelli e Gilmar Morais por cederem seus rebanhos, ao Médico Veterinário Ildemar Brayer Pereira, pelo treinamento realizado, bem como à FAPESC (Fundação de Apoio à Pesquisa Científica e Tecnológica do Estado de Santa Catarina), pela bolsa de mestrado concedida.

\section{NOTAS INFORMATIVAS}

\section{Reservado ao parecer CEUA.}

\section{REFERÊNCIAS}

AULDIST, M. J.; PYMAN, M. F. S.; GRAINGER, C.; MACMILLAN, K. L. et al. Comparative reproductive performance and early lactation productivity of Jersey $\mathrm{x}$ Holstein cows in predominantly Holstein herds in a pasture-based dairying system. Journal of dairy science, v. 90, n. 10, p. 4856-62, 2007. Elsevier. Disponível em: $<$ http://www.ncbi.nlm.nih.gov/pubmed/17881 709>. Acesso em: 14/11/2013.

BJELLAND, D. W.; WEIGEL, K. A; HOFFMAN, P. C.; et al. Production, reproduction, health, and growth traits in backcross Holstein $\times$ Jersey cows and their Holstein contemporaries. Journal of dairy science, v. 94, n. 10, p. 5194-203, 2011. Elsevier. Disponível em: $<$ http://www.ncbi.nlm.nih.gov/pubmed/21943 769>. Acesso em: 7/11/2013.
CAMPOS, R. V. Parâmetros genéticos para caracteristicas lineares de tipo e produtivas em vacas da raça holandesa no Brasil, 2012.

CARAVIELLO, D. Z.; WEIGEL, K. A.; GIANOLA, D. et al. Analysis of the Relationship Between Type Traits , Inbreeding, and Functional Survival in Jersey Cattle Using a Weibull Proportional Hazards Model. Journal of Dairy Science, v. 86 , n. 9, p. 2984-2989, 2003. Elsevier. Disponível em: <http://dx.doi.org/10.3168/jds.S00220302(03)73896-X>.

CARAVIELLO, D. Z.; WEIGEL, K. A.; GIANOLA, D. et al. Analysis of the Relationship Between Type Traits and Functional Survival in US Holstein Cattle Using a Weibull Proportional Hazards Model. Journal of Dairy Science, v. 87, n. 8, p. 2677-2686, 2004. Elsevier. Disponível em: <http://dx.doi.org/10.3168/jds.S00220302(04)73394-9>.

COSTA, C. N.; COBUCI, J. A.; SANTOS, G. G. DOS; et al. Sumário nacional de touros da raça Holandesa - 2013. 2013.

ESTEVES, A. M. C.; BERGMANN, J. A G.; DURÃES, M. C.; COSTA, C. N.; SILVA, H. $\mathrm{M}$. et al. Correlações genéticas e fenotípicas entre características de tipo e produção de leite em bovinos da raça Holandesa. Arquivo Brasileiro de Medicina Veterinaria e Zootecnia, v. 56, p. 529-535, 2004.

FELIPPE, E. W. Comparação de vacas mestiças das raças Holandesa $X$ Jersey com vacas puras quanto à eficiência produtiva e reprodutiva, 2013.

HARRIS, B. L.; FREEMAN, A E.; METZGER, E. et al. Genetic and phenotypic parameters for type and production in Guernsey dairy cows. Journal of dairy science, v. 75, p. 1147-1153, 1992.

HEINS, B. J.; HANSEN, L. B.; HAZEL, A R.; et al. Short communication: Jersey $x$ Holstein crossbreds compared with pure Holsteins for body weight, body condition score, fertility, and survival during the first three lactations. Journal of dairy science, v. 95, n. 7, p. 4130-5, 2012. Elsevier. Disponível 
<http://www.ncbi.nlm.nih.gov/pubmed/22720 969>. Acesso em: 7/11/2013.

HEINS, B. J.; HANSEN, L. B.; SEYKORA, A J.; et al. Crossbreds of Jersey $x$ Holstein compared with pure Holsteins for body weight, body condition score, dry matter intake, and feed efficiency during the first one hundred fifty days of first lactation. Journal of dairy science, v. 91, n. 9 , p. 3716-3722, 2008. Elsevier. Disponível em: $<$ http://dx.doi.org/10.3168/jds.2008-1094>.

HEINS, B. J.; HANSEN, L. B.; SEYKORA, A. J.; et al. Short communication : Jersey $x$ Holstein crossbreds compared with pure Holsteins for production, mastitis, and body measurements during the first 3 lactations. Journal of Dairy Science, v. 94, n. 1, p. 501-506, 2011. Elsevier. Disponível em: <http://dx.doi.org/10.3168/jds.2010-3232>.

LOPEZ-VILLALOBOS, N.; GARRICK, D. J.; HOLMES, C. W.; BLAIR, H. T.; SPELMAN, R. J. et al. Effects of selection and crossbreeding strategies on industry profit in the New Zealand dairy industry. Journal of dairy science, v. 83, n. 1, p. 164-72, 2000. Elsevier. Disponível em: <http://www.ncbi.nlm.nih.gov/pubmed/10659 976>. Acesso em: 9/12/2014.

NĚMCOVÁ, E.; ŠTíPKOVÁ, M.; ZAVADILOVÁ, L.; BOUŠKA, J.; VACEK, M. et al. The relationship between somatic cell count, milk production and six linearly scored type traits in Holstein cows. Czech Journal of Animal Science, v. 52, n. 1, p. 437-446, 2007.

PÉREZ-CABAL, M. A.; ALENDA, R. Genetic Relationships between Lifetime Profit and Type Traits in Spanish Holstein Cows., p. 3480-3491, 2002.

SAWA, A; BOGUCKI, M.; KRĘŻELCZOPEK, S.; NEJA, W. et al. Relationship between Conformation Traits and Lifetime Production Efficiency of Cows. ISRN veterinary science, v. 2013, p. 124690, 2013. Disponível em: $<$ http://www.pubmedcentral.nih.gov/articlere nder.fcgi?artid $=3710600 \&$ tool $=$ pmcentrez\& $r$ endertype $=$ abstract $>$.

THALER NETO, A., PARIZOTTO FILHO, R., PELIZZA, A. et al. Cruzamentos em gado leiteiro. , 2013. Londrina: Anais IV Simpósio Brasil Sul de Bovinocultura de
Leite.

THERON, H. E.; MOSTERT, B. E. Genetic analyses for conformation traits in South African Jersey and Holstein cattle. South African Journal of Animal Sciences, v. 34, n. Supplement 2, p. 47-49, 2004.

VALLOTO, A. A.; NETO, P. G. R. Avaliação da conformação ideal das vacas leiteiras. Curitiba: SENAR-PR, 2012.

VANCE, E. R.; FERRIS, C. P.; ELLIOTT, C. T.; MCGETTRICK, S. A; KILPATRICK, D. J. et al. Food intake, milk production, and tissue changes of Holstein-Friesian and Jersey $\times$ Holstein-Friesian dairy cows within a medium-input grazing system and a highinput total confinement system. Journal of dairy science, v. 95, n. 3, p. 1527-44, 2012. Elsevier. Disponível em: <http://www.ncbi.nlm.nih.gov/pubmed/22365 233>.

ZINK, V.; ŠTÍPKOVÁ, M.; LASSEN, J. et al. Genetic parameters for female fertility, locomotion, body condition score, and linear type traits in Czech Holstein cattle. Journal of dairy science, v. 94, p. 5176-82, 2011. Disponível em: <http://www.ncbi.nlm.nih.gov/pubmed/21943 767>. 